\title{
CYTOPHAGIC HISTIOCYTIC PANNICULITIS ASSOCIATED WITH HBE HEMOGLOBINOPATHY IN A PATIENT WITH HEMOPHAGOCYTIC SYNDROME
}

\author{
by Swati Sharma, Manna Valiathan, Sushama Belurkar, Raviraj Acharya, Swati Aggarwal
}

comment:

Prof. Hubert Daisley
University of the West Indies, Trinidad and Tobago
E-mail: profhdjr@yahoo.com

\author{
Source of Support: \\ Nil \\ Competing Interests: \\ None
}

The cutaneous manifestations of hemophagocytic lymphohistiocytosis are varied and non-specific. Many patients with the disease have a non-specific rash that is often vaguely termed maculopapular although it has also been described as ranging from erythroderma to generalized purpuric macules and papules, and morbilliform eruptions [1].

Deep subcutaneous infiltration by histiocytes/lymphocytes giving rise to erythromatous nodules described as cytophagic histiocytic panniculitis by Swati Sharma, et al [2] is yet another skin manifestation of hemophagocytic lymphohistiocytosis [3].

Hemophagocytic lymphohistiocytosis is a rare but potentially fatal disease of normal but overactive histiocytes and lymphocytes that affects all age groups although most reports describe the entity in infants. Fever, hepatosplenomegaly, pancytopenia, lymphadenopathy and rash often comprise the initial presentation. There are two forms of the disease, namely one that is hereditary (or primary) and the other which is acquired (or secondary).

Primary hemophagocytic lymphohistiocytosis is a heterogeneous autosomal recessive disorder found to be more prevalent with parental consanguinity, and is typically seen in infancy and early childhood [4]

Acquired hemophagocytic lymphohistiocytosis occurs after strong immunologic activation, such as that which can occur with systemic infection, immunodeficiency, or underlying malignancy. Both primary and secondary hemophagocytic lymphohistiocytosis are characterized by the overwhelming activation of normal $\mathrm{T}$ lymphocytes and macrophages, invariably leading to clinical and hematologic alterations and death in the absence of treatment.

The pathological hallmark of this disease is the aggressive proliferation of activated macrophages and histiocytes, which phagocytosis other cells, namely RBCs, WBCs, and platelets, leading to the clinical symptoms. The uncontrolled growth is nonmalignant and does not appear clonal in contrast to the lineage of cells in Langerhans cells diseases [5].

The reticulo-endothelial system namely spleen, lymph nodes, bone marrow, liver, gut, skin, and microglia's cells in the brain and spinal cord are preferential sites of involvement. This disorder may be viewed as a highly stimulated, but ineffective, immune response to antigens, which results in life-threatening cytokine storm. A current accepted theory of hemophagocytic lymphohistiocytosis involves an inappropriate immune reaction caused by proliferating and activated $\mathrm{T}$ cells associated with macrophage activation and inadequate apoptosis of immunogenic cells. There are convincing evidence for the role of perforin and natural killer (NK) cells in the hemophagocytic lymphohistiocytosis subtypes. Perforin or poreforming protein (PFP), gene map location 10q22, is one of the major cytolytic proteins of granules contained in cytotoxic cells [6].

When activated by an antigen, NK cells release granules that contain perforin and granzymes, which form pores in the target cell membrane and cause osmotic lysis and protein degradation, respectively. Patients with perforin deficiency may have impaired defenses against intracellular pathogens and cancers, as has been demonstrated in animal models [7]. Although the mechanism is yet to be determined, decreased NK cell activity results in increased T-cell activation and expansion, resulting in cytokine storm with production of large quantities of cytokines, including interferon gamma (IFNg), tumor necrosis factor-a (TNF-a), and granulocytemacrophage colony-stimulating factor (GM-CSF). This causes sustained macrophage activation and tissue infiltration as well as production of interleukin-1 (IL-1) and interleukin-6 (IL-6). The resulting inflammatory reaction causes extensive damage and the associated symptoms.

Epstein-Barr virus, is the pathogen that most commonly triggers infection-associated, secondary hemophagocytic lymphohistiocytosis [8] Hemophagocytic lymphohistiocytosis can also be acquired from other infectious and inflammatory conditions $[9,10]$.

The familial form of hemophagocytic lymphohistiocytosis is a rare autosomal recessive disorder that has been classified into 6 different types based on genetic linkage analysis and chromosomal localization; 5 specific genetic defects have been identified, which account for approximately $90 \%$ of all patients.

Type 1 is due to a gene defect on chromosome 9, type 2 is due to mutations in the perforin gene, type 3 is due to mutations in the Munc-13-4 (UNC13D) gene, type 4 is due to mutations in the syntaxin 11 (STX11) gene, and type 5 is due to mutations in the gene encoding syntaxin-binding protein 2 (STXBP-2) [11,12]. 
The diagnostic criteria set forth by the Histiocyte Society for inclusion in the International Registry for Hemophagocytic Lymphohistiocytosis (HLH) is as follows [13].

1. Fever - Seven or more days of a temperature as high as $38.5^{\circ} \mathrm{C}$ $\left(101.3^{\circ} \mathrm{F}\right) 2$ Splenomegaly - A palpable spleen greater than $3 \mathrm{~cm}$ below the costal margin

3. Cytopenia - Counts below the specified range in at least 2 of the following cell lineages:

Absolute neutrophils less than $1000 / \mu \mathrm{L}$

Platelets less than $100,000 / \mu \mathrm{L}$

Hemoglobin less than $9.0 \mathrm{~g} / \mathrm{dL}$

4. Hypofibrinogenemia or hypertriglyceridemia - [1] Fibrinogen less than $1.5 \mathrm{~g} / \mathrm{L}$ or levels greater than 3 standard deviations below the age adjusted reference range value or [2] fasting triglycerides greater than $2 \mathrm{mmol} / \mathrm{L}$ or levels greater than 3 standard deviations above the age-adjusted reference range value

5.Hemophagocytosis - Must have tissue demonstration from lymph node, spleen, or bone marrow without evidence of malignancy.

Three additional criteria are introduced namely, [6] low/absent NK-cell-activity, [7] hyperferritinemia, and [8] high-soluble interleukin-2-receptor levels [14].

Altogether five of these eight criteria must be met before the diagnosis of hemophagocytic lymphohistiocytosis can be made. Other presenting symptoms include CNS involvement with seizures, ataxia, hemiplegia or mental status changes [15] and clinical abnormalities such as diarrhea, vomiting, jaundice, coagulopathy, due infiltration of other organs or the reticular endothelial system namely gut, bone marrow, liver, spleen and lympnode [16]. Liver involvement and the thrombocytopenia induced by the phagocytic activity of these histiocytes, and splenic activity, leads to life threatening coagulopathy, which is a common cause of mortality in these patients.

$\mathrm{T}$ cell lymphomas may present with skin manifestation similar to those seen in hemophagocytic lymphohistiocytosis. A newly described entity namely subcutaneous panniculitis- like $\mathrm{T}$ cell lymphoma can be confused with the benign proliferative immune condition hemophagocytic lymphohistiocytosis (HLH), and efforts should be made to differentiate them [17].

Hemophagocytic lymphohistiocytosis (HLH) is a rare life threatening condition and efforts should be made to have prompt diagnosis. Therapy should be instituted at a very early stage. Familial hemophagocytic lymphohistiocytosis is uniformly fatal if not treated; the median survival time reported in various studies is 2-6 months after diagnosis. Remission is always temporary, as the disease inevitably returns.

The outcomes of secondary hemophagocytic lymphohistiocytosis vary $[18,19]$.

Therapy includes the use of anti-inflammatory agent such as steroids, and anti- neoplastic agents [20]

Intravenous immunoglobulin (IVIG) is also used as an effective form of therapy. Bone marrow transplant is the only hope for cure. Supportive therapy is institutive where ever necessary for example in the treatment of thrombocytopenia and infections. Opportunistic infections especially fungal represent an important cause of death in this population [21].

\section{REFERENCES}

1. Morrell DS, Pepping MA, Scott JP, Esterly NB, Drolet BA: Cutaneous Manifestations of Hemophagocytic Lymphohistiocytosis Arch Dermatol. 2002;138:1208-12.

2. Sharma S, Valiathan M, Belurkar S, Acharya R, Aggarwal

$\mathrm{S}$ : Cytophagic histiocytic panniculitis associated with $\mathrm{HBe}$ hemoglobinopathy in a patient with hemophagocytic syndrome. Our Dermatol Online. 2013;4:351-3.

3. Lipsker D, Grosshans E: [Histiocytic cytophagic panniculitis]. Presse Med. 1997;26:1987-91.

4. Henter JI, Samuelsson A, Ericson K, Nilsson-Ardnor S, Elinder G, Fadeel B: Familial hemophagocytic lymphohistiocytosis: diagnosis, treatment and pathophysiological mechanisms Lakartidningen. 2000 Mar 22;97(12):1405-8.

5. de Graaf JH, Egeler RM: New insights into the pathogenesis of Langerhans cell histiocytosis. Curr Opin Pediatr. 1997;9:46-50.

6. Trapani JA, Thia KY, Andrews M, Davis ID, Gedye C, Parente P, et al: Human perforin mutations and susceptibility to multiple primary cancers. Oncoimmunology. 2013;2:e24185.

7. Bryceson YT, Rudd E, Zheng C, Edner J, Ma D, Wood SM, et al: Defective cytotoxic lymphocyte degranulation in syntaxin-11 deficient familial hemophagocytic lymphohistiocytosis 4 (FHL4) patients. Blood. 2007;110:1906-15.

8. Weitzman S: Approach to hemophagocytic syndromes. Hematology Am Soc Hematol Educ Program. 2011:178-83.

9. Dilber E, Erduran E, Kalyoncu M, Aynaci FM, Okten A, Ahmetoğlu A: Hemophagocytic syndrome as an initial presentation of miliary tuberculosis without pulmonary findings.Scand J Infect Dis. 2002;34:689-92.

10. Yishan Zheng Y, Yongfeng Yang Y, Wei Zhao W, Wang H: Novel Swine-Origin Influenza A(H1N1) Virus-Associated Hemophagocytic Syndrome-A First Case Report. Am J Trop Med Hyg. 2010;82:743-5. 11. Spísek R, Mejstríková E, Formánková R, Zizková H, Vávra V, Hrusák $\mathrm{O}$, et al: Familial haemophagocytic lymphohistiocytosis caused by perforin deficit can be successfully treated by haematopoietic stem cell transplantation--the first diagnosed case in the Czech Republic.Cas Lek Cesk. 2006;145:50-4.

12. Bryceson YT, Rudd E, Zheng C, Edner J, Ma D, Wood SM, et al: Defective cytotoxic lymphocyte degranulation in syntaxin-11 deficient familial hemophagocytic lymphohistiocytosis 4 (FHL4) patients. Blood. 2007;110:1906-15.

13. Henter JI, Aricò M, Egeler RM, Elinder G, Favara BE, Filipovich $\mathrm{AH}$, et al: HLH-94: a treatment protocol for hemophagocytic lymphohistiocytosis. HLH study Group of the Histiocyte Society. Med Pediatr Oncol. 1997;28:342-7.

14. Henter JI, Horne A, Aricó M, Egeler RM, Filipovich AH, Imashuku S, et al: HLH-2004: Diagnostic and therapeutic guidelines for hemophagocytic lymphohistiocytosis. Pediatr Blood Cancer. 2007;48:124-31.

15. Horne AC, Trottestam H, Aricò M, Egeler RM, Filipovich $\mathrm{AH}$, Gadner H, et al: Frequency and spectrum of central nervous system involvement in 193 children with haemophagocytic lymphohistiocytosis Br J Haematol. 2008;140:327-35.

16. Ost A, Nilsson-Ardnor S, Henter JI: Autopsy findings in 27 children with haemophagocytic lymphohistiocytosis. Histopathology. 1998;32:310-6.

17. Salhany KE, Macon WR, Choi JK, Elenitsas R, Lessin SR, Felgar RE, et al: Subcutaneous panniculitis-like T-cell lymphoma: clinicopathologic, immunophenotypic, and genotypic analysis of alpha/beta and gamma/delta subtypes. Am J Surg Pathol. 1998;22:881-93.

18. Imashuku S, Hibi S, Ohara T, Iwai A, Sako M, Kato M, et al: Effective control of Epstein-Barr virus-related hemophagocytic lymphohistiocytosis with immunochemotherapy. Histiocyte Society. Blood. 1999;93:1869-74.

19. Weitzman S: Approach to hemophagocytic syndromes. Hematology Am Soc Hematol Educ Program. 2011;2011:178-83.

20. Trottestam H, Horne AC, Arico MR, Maarten Egeler M, Filipovich AH, Gadner H: Chemoimmunotherapy for hemophagocytic lymphohistiocytosis: long-term results of the HLH-94 treatment protocol. Blood. 2011;118:4577-84.

21. Henter J-I: Sweden. Histiocyte Society HLH 2004hemophagocytic lymphohistiocytosis Study Group -Treatment Protocol Of The Second International HLH Study 2004. 